\title{
AMINOGLYCOSIDE RESISTANCE DETERMINANTS IN MULTIRESISTANT ESCHERICHIA COLI AND KLEBSIELLA PNEUMONIAE CLINICAL ISOLATES FROM TURKISH AND SYRIAN PATIENTS
}

\author{
OSMAN SEZER CIRIT ${ }^{1 *}$, MARTA FERNÁNDEZ-MARTínEZ ${ }^{2}$, BUKET YAYLA $^{3}$ and \\ LUIS MARTÍNEZ-MARTÍNEZ ${ }^{4}$ \\ ${ }^{1}$ Microbiology Laboratory, Gaziantep Dr. Ersin Arslan Training and Research Hospital, \\ Gaziantep, Turkey \\ ${ }^{2}$ Service of Microbiology, Hospital Universitario Marqués de Valdecilla, Santander, Spain \\ ${ }^{3}$ Clinical Microbiology Department, School of Medicine, Baskent University, \\ Adana, Turkey \\ ${ }^{4}$ Clinical Unit of Microbiology, Department of Microbiology, Hospital Universitario \\ Reina Sofía, Instituto Maimónides de Investigación Biomédica de Córdoba (IMIBIC), \\ Universidad de Córdoba, Córdoba, Spain
}

(Received: 25 November 2018; accepted: 18 December 2018)

Escherichia coli and Klebsiella pneumoniae are frequently found resistance to aminoglycosides in Turkey. The aim of this study was to investigate aminoglycoside resistance in clinical isolates of E. coli and K. pneumoniae from Turkey using both phenotypic and genotypic methods and screening for the prevalence of gene coding for common aminoglycoside-modifying enzymes (AMEs) and 16S rRNA methylase genes. A total of 88 consecutive, non-duplicated E. coli $(n=65)$ and $K$. pneumoniae $(n=23)$ isolates showing resistance or intermediate resistance to amikacin and/or gentamicin were collected between October 2013 and May 2015 from clinical samples received at Gaziantep Dr. Ersin Arslan Training and Research Hospital. Seventeen isolates were obtained from Syrian patients. Isolates resistant to any of the two aminoglycosides were tested by PCR for seven AME genes, and 22 isolates with amikacin $\mathrm{MIC} \geq 16 \mathrm{mg} / \mathrm{L}$ were also tested for $16 \mathrm{~S}$ rRNA methylase genes. In $E$. coli isolates, the most frequent genes were $a a c\left(6^{\prime}\right)-I b$ (50 strains; 76.9\%) and $a a c(3)-I I a$ (40 strains; $70.7 \%$ ), followed by aph ( $\left.3^{\prime}\right)$-Ia (5 strains; $7.6 \%$ ) and ant ( $\left.2^{\prime \prime}\right)$-Ia (2 strains; $3.1 \%)$. Among the 23 resistant $K$. pneumoniae isolates, the most prevalent gene was aac (3')-IIa (87.0\%) followed by aac (6')-Ib (73.9\%) and aph(3')-Ia (8.6\%). The $r m t C$ gene was detected in one $K$. pneumoniae isolate. Resistance to aminoglycosides in clinical isolates of $E$. coli and $K$. pneumoniae from our center is predominantly caused

\footnotetext{
*Corresponding author; E-mail: osmancirit@yahoo.com
} 
by AAC(6')-Ib and AAC(3)-II enzymes, while the occurrence of 16S rRNA methylases is so far limited.

Keywords: aminoglycoside-modifying enzyme, 16S rRNA methyltransferase, E. coli, K. pneumoniae

\section{Introduction}

Aminoglycosides are a large family of drugs that act at the ribosome by inhibiting one or more of the biochemical steps involved in translation. They are extensively used in the treatment of serious bacterial infections, particularly in combination with $\beta$-lactams or glycopeptides [1]. The increasing problem of multiresistance in Gram-negative bacteria and the introduction of new aminoglycoside analogues (e.g., plazomicin) warrant new studies aimed at understanding aminoglycoside resistance [2].

According to the Central Asian and Eastern European Survillance of Antimicrobial Resistance (CAESAR) annual report 2016, Escherichia coli and Klebsiella pneumoniae had high resistance to the third-generation cephalosporins, aminoglycosides, and fluoroquinolones in Turkey [3].

In terms of frequency, the most important determinant of aminoglycoside resistance in E. coli, K. pneumoniae, and many other Gram-negative bacteria is aminoglycoside-modifying enzymes (AMEs), of which three classes are defined according to their modifying activities: acetyltransferases (AAC), nucleotidyltransferases (ANT), and phosphotransferases (APH) [4]. Other mechanisms conferring aminoglycoside resistance include active efflux of the antimicrobial and reduced intake into the bacterial cell, and production of several 16S rRNA methylases with ArmA, RmtB, and RmtC being the most widespread [2, 5].

Genes encoding AMEs and 16S rRNA methylases are located on mobile genetic elements along with other resistance determinants, such as extendedspectrum $\beta$-lactamases (ESBLs) and carbapenemases, contributing to explain multidrug resistance in clinical isolates [6].

The aim of this study was to investigate aminoglycoside resistance in E. coli and $K$. pneumoniae using both phenotypic and genotypic methods.

\section{Materials and Methods}

Bacterial isolates

A total of 88 consecutive, non-duplicated E. coli and K. pneumoniae isolates collected from clinical samples between October 2013 and May 2015 at Gaziantep 
Dr. Ersin Arslan Training and Research Hospital and showing resistance or decreased susceptibiliy to amikacin and/or gentamicin were studied. Seventeen isolates were from Syrian patients $(9 \mathrm{~K}$. pneumoniae and 8 E. coli).

\section{Antimicrobial susceptibility testing}

The strains were identified by both conventional methods and Vitek 2 Compact system (BioMérieux, France). Antibiotic susceptibility (aminoglycosides, carbapenems, and ciprofloxacin) and ESBL production of isolates were tested by the Vitek 2 Compact system. The isolates were selected based on Vitek 2 results. In addition, the disk diffusion method was also performed for amikacin, gentamicin, and tobramycin. The results were interpreted using clinical breakpoints as defined by the Clinical Laboratory and Standards Institute [7]. E. coli ATCC 25922 and Pseudomonas aeruginosa ATCC 27853 were used as quality control strains.

\section{Molecular characterization of aminoglycoside resistance genes}

Isolates resistant to any of the indicated aminoglycosides were tested by PCR for seven AME genes. Twenty-two isolates (19 E. coli and 3 K. pneumoniae) with a minimum inhibitory concentration (MIC) of amikacin $\geq 16 \mathrm{mg} / \mathrm{L}$ were also tested for 16S rRNA methylase genes. As a control, 10 isolates susceptible to the indicated aminoglycosides were also used in the PCR analysis. Sets of primers for the following genes were included in the PCR assay: aac(3)-Ia, aac(3)-IIa, aac(6)-Ib, ant(2)-Ia, aph(3)-Ia, aph(3)-IIa, aph(3)-Via, armA, rmtB, rmtC, and $r m t D$. The primers for AME and methyltransferase genes and their expected amplicon sizes are shown in Tables I and II.

Genomic DNA was extracted using an InstaGeneTM Matrix Kit (Bio-Rad, Madrid, Spain) according to the manufacturer's instructions. Then, $2 \mu 1$ of DNA were added to a reaction mixture containing $1 \times$ PCR buffer, $1.5 \mathrm{mM} \mathrm{MgCl}_{2}$, $200 \mu \mathrm{M}$ deoxynucleoside triphosphate, $0.5 \mu \mathrm{M}$ of each primer, and $1 \mathrm{U}$ of Taq DNA Polymerase (Bioline, London, UK). Amplification conditions were $94{ }^{\circ} \mathrm{C}$ for 5 min, followed by 30 cycles of $94^{\circ} \mathrm{C}$ for $30 \mathrm{~s}, 55^{\circ} \mathrm{C}$ for $30 \mathrm{~s}\left[60^{\circ} \mathrm{C}\right.$ for $\left.a a c(6)-\mathrm{Ib}\right]$ and $72{ }^{\circ} \mathrm{C}$ for $1 \mathrm{~min}$, and a final elongation at $72{ }^{\circ} \mathrm{C}$ for $10 \mathrm{~min}$. PCR products were analyzed on $1.5 \%(\mathrm{w} / \mathrm{v})$ agarose gels stained with ethidium bromide.

\section{Results}

Thirty-three (50.7\%) E. coli isolates were resistant to amikacin by Vitek 2 compared to 25 (38.4\%) by disk diffusion. Eight (34.7\%) K. pneumoniae isolates 
Table I. Primers used in the detection of aminoglycoside-modifying enzyme (AME) and expected amplicon sizes

\begin{tabular}{|c|c|c|c|c|}
\hline Gene & & DNA sequence $\left(5^{\prime}-3^{\prime}\right)$ & Product (bp) & Reference \\
\hline \multirow[t]{2}{*}{$a a c\left(6^{\prime}\right)-I b$} & aac6'-Ib-F & TTGCGATGCTCTATGAGTGGCTA & 482 & [8] \\
\hline & aac6'-Ib-R & CTCGAATGCCTGGCGTGTTT & & \\
\hline \multirow[t]{2}{*}{ aac(3)-IIa } & aac3-IIa-F & GGCAATAACGGAGGCGCTTCAAAA & 563 & [1] \\
\hline & aac3-IIa-R & TTCCAGGCATCGGCATCTCATACG & & \\
\hline \multirow[t]{2}{*}{$a a c(3)-I a$} & aac3-Ia-F & GCAGTCGCCCCTAAAACAAA & 464 & [1] \\
\hline & aac3-Ia-R & САCTTCTTCCCGTATGCCCAACTT & & \\
\hline \multirow[t]{2}{*}{$\operatorname{aph}\left(3^{\prime}\right)-V I a$} & aph3'-VIa-F & AAAGCGATCAATGCAAAACC & 310 & [1] \\
\hline & aph3'-VIa-R & TATCCGTGATATCGCCATGA & & \\
\hline \multirow[t]{2}{*}{$\operatorname{ant}\left(2^{\prime \prime}\right)-I a$} & ant $2 "$-Ia-F & CGTCATGGAGGAGTTGGACT & 303 & [1] \\
\hline & ant2"-Ia-R & CGCAAGACCTCAACCTTTTC & & \\
\hline \multirow[t]{2}{*}{$\operatorname{aph}\left(3^{\prime}\right)-I a$} & ant2"-Ia-F & CGAGCATCAAATGAAACTGC & 624 & [1] \\
\hline & ant2"-Ia-R & GCGTTGCCAATGATGTTACAG & & \\
\hline \multirow[t]{2}{*}{$\operatorname{aph}\left(3^{\prime}\right)-I I a$} & aph3'-Ia-F & GAACAAGATGGATTGCACGC & 680 & [1] \\
\hline & aph3'-Ia-R & GCTCTTCAGCAATATCACGG & & \\
\hline
\end{tabular}

Table II. Primers used in the detection of methyltransferase genes and expected amplicon sizes

\begin{tabular}{lllcc}
\hline Gene & & \multicolumn{1}{c}{ DNA sequence $\left(5^{\prime}-3^{\prime}\right)$} & Product (bp) & Reference \\
\hline$a r m A$ & armA-F & CAAATGGATAAGAATGATGTT & 777 & {$[9]$} \\
& armA-R & TTATTTCTGAAATCCACT & \multirow{2}{*}{ T59 } & {$[10]$} \\
$r m t B$ & rmtB-F & TCAACGATGCCCTCACCTC & & \\
& rmtB-R & GCAGGGCAAAGGTAAAATCC & 711 & {$[11]$} \\
$r m t C$ & rmtC-F & CGAAGAAGTAACAGCCAAAG & 730 & {$[12]$} \\
& rmtC-R & ATCCCAACATCTCTCCCACT & 730 \\
\hline
\end{tabular}

were resistant to amikacin by Vitek 2 compared to 13 (56.5\%) by the disk diffusion. Resistance to gentamicin among E. coli and K. pneumoniae was similar by disk diffusion and Vitek 2 [47 isolates each $(72.3 \%)$ and 21 isolates each (91.3\%), respectively]. Resistance of E. coli and K. pneumoniae to tobramycin, as defined by disk diffusion, was $100 \%$ and $93.8 \%$, respectively (Table III). Resistance rates of E. coli and K. pneumoniae to carbapenems and ciprofloxacin are also shown in Table IV. Fifty-six (86.1\%) E. coli and 22 (95.6\%) K. pneumoniae isolates were found positive for ESBL production.

Overall, the most frequent genes were $a a c\left(6^{\prime}\right)-I b$ (67 strains; 76.1\%) and aac(3)-IIa (66 strains; 75.0\%), followed by aph(3')-Ia (7 strains; $8.0 \%)$ and ant $\left(2^{\prime \prime}\right)$-Ia (2 strains; $\left.2.3 \%\right)$. Among the isolates from Syrian patients (17 strains), the 
most prevalent gene was aac(3)-IIa (82.3\%), followed by aac $\left(6^{\prime}\right)-I b(64.7 \%)$ and $\operatorname{aph}\left(3^{\prime}\right)-I a(5.8 \%)$.

The most frequent AME gene in 65 resistant $E$. coli isolates was aac $\left(6^{\prime}\right)-I b$, identified in $50(76.9 \%)$ isolates, followed by aac(3)-IIa in $46(70.7 \%)$ isolates, aph $\left(3^{\prime}\right)-I a$ in $5(7.6 \%)$, and ant(2")-Ia in $2(3.1 \%)$ isolates. The genes aac(3)-Ia, $a p h\left(3^{\prime}\right)-V I a$, and $a p h\left(3^{\prime}\right)-I I a$ were not found in E. coli isolates. Among the 23 resistant $K$. pneumoniae isolates, the prevalence of AME genes was as follows: $a a c(3)-I I a$ was the most frequent one, identified in $20(87.0 \%)$ isolates, followed by $a a c\left(6^{\prime}\right)-I b$ in $17(73.9 \%)$ isolates and $a p h\left(3^{\prime}\right)-I a$ in $2(8.6 \%)$. The genes $a a c(3)-I a$,

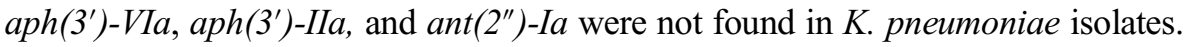

In three (one $K$. pneumoniae and two $E$. coli) isolates, none of the seven investigated AME genes was detected. One of those E. coli isolates had an intermediate category to gentamicin by Vitek 2 but was susceptible to that agent by disk diffusion. The other $E$. coli isolate was resistant to all tested aminoglycosides. We detected the $r m t C$ gene in the $K$. pneumoniae isolate.

Fifty-five isolates were presented with more than one gene. The combination of $a a c\left(6^{\prime}\right)-I b$ and $a a c(3)-I I a$ was the most common one for both E. coli (33 isolates; 51\%) and $K$. pneumoniae (14 isolates; 61\%) isolates, followed by aac(3)-IIa and aph(3')-Ia in E. coli (5 isolates; 6\%) and K. pneumoniae (1 isolate; $4.3 \%)$. One $E$. coli isolate harbored four genes: $a a c\left(6^{\prime}\right)-I b+a a c(3)-I I a+a p h\left(3^{\prime}\right)-I a$

Table III. The resistance rates of aminoglycosides in E. coli and K. pneumoniae isolates

\begin{tabular}{lccccc}
\hline & \multicolumn{2}{c}{ E. coli } & & \multicolumn{2}{c}{ K. pneumoniae } \\
\cline { 2 - 3 } \cline { 5 - 6 } & Disk diffusion & Vitek 2 & & Disk diffusion & Vitek 2 \\
\hline Amikacin & 50.7 & 38.4 & & 34.7 & 56.5 \\
Gentamicin & 72.3 & 72.3 & & 91.3 & 91.3 \\
Tobramycin & 93.8 & ND & & 100 & ND \\
\hline
\end{tabular}

Note: ND: non-detected.

Table IV. The antimicrobial resistance rates of carbapenems, ciprofloxacin, and ESBL production of $E$. coli and $K$. pneumoniae isolates by Vitek 2 method

\begin{tabular}{lcc}
\hline & E. coli & K. pneumoniae \\
\hline ESBL & 86.1 & 95.6 \\
Imipenem & 4.6 & 17.3 \\
Meropenem & 4.6 & 17.3 \\
Ertapenem & 9.2 & 26.0 \\
Ciprofloxacin & 96.9 & 69.5 \\
\hline
\end{tabular}

Note: ESBL: extended-spectrum $\beta$-lactamase. 
$+\operatorname{ant}\left(2^{\prime \prime}\right)-I a$. One $K$. pneumoniae isolate harbored three genes: $a a c\left(6^{\prime}\right)-I b+$ $\operatorname{aac}(3)-I I a+\operatorname{aph}\left(3^{\prime}\right)-I a$.

\section{Discussion}

According to the CAESAR annual report 2016, the percentage of aminoglycoside (amikacin, gentamicin, and tobramycin) resistance was $29 \%$ for $E$. coli and $45 \%$ for $K$. pneumoniae among blood and cerebrospinal fluid isolates in Turkey in 2014 [3].

In this study, a total of $72.3 \%$ and $50.7 \%$ of the $E$. coli isolates were resistant or intermediate to gentamicin and amikacin by Vitek 2. For K. pneumonia, the prevalence of resistance was $91.3 \%$ and $34.7 \%$ to gentamicin and amikacin, respectively. In both E. coli and $K$. pneumoniae, the prevalence of reduced susceptibility was higher for tobramycin.

The finding of this study that the most frequent AME genes were $a a c\left(6^{\prime}\right)-I b$ followed by aac(3)-IIa, aph (3')-Ia, and ant(2")-Ia is in line with a Spanish study, in which the most prevalent AME genes in 420 ESBL-positive E. coli and 139 ESBL-positive $K$. pneumoniae were $a a c\left(6^{\prime}\right)-I b$ ( $16.2 \%$ and $44.6 \%$, respectively) and $\operatorname{aac}(3)-I I a$ (14.7\% and $43.1 \%$, respectively) [13]. In an another Spanish study, including $257 \mathrm{E}$. coli isolates resistant to amoxicillin/clavulanic acid, the most prevalent AME genes were $a a c\left(6^{\prime}\right)-I b$ followed by $a p h\left(3^{\prime}\right)-I a$, $\operatorname{ant}\left(2^{\prime \prime}\right)-I a$, and $a a c\left(3^{\prime}\right)-\operatorname{II} a(2)$. However, in a study from Norway, PCR screening for AME genes showed that the most prevalent AME gene in both E. coli and K. pneumoniae was $a a c(3)-I I$, followed by $a a c\left(6^{\prime}\right)-I b$, whereas ant (2") $-I a$ was only identified in three E. coli isolates [6].

The $a a c\left(6^{\prime}\right)-I b$ gene, which is probably the most clinically relevant AAC in Enterobacteriaceae, is responsible for resistance to amikacin and tobramycin, but not gentamicin [4]. In this study, 17 out of the 18 (94.4\%) isolates that were only positive for $a a c\left(6^{\prime}\right)-I b$ expressed phenotypic resistance to amikacin. Among the isolates with the $a a c\left(6^{\prime}\right)-I b$ gene, the prevalence of ESBL production and ciprofloxacin resistance was $91 \%$ and $94 \%$, respectively. This finding supports the fact that the $a a c\left(6^{\prime}\right)-I b$ gene is usually associated with quinolone resistance genes or $\beta$-lactamase genes [4]. In another study in Turkey, the authors indicated that an $a a c\left(6^{\prime}\right)-I V$ enzyme, presumably related to $\mathrm{AAC}\left(6^{\prime}\right)-\mathrm{Ib}$, was the most common AME in Klebsiella spp. (37.5\%), whereas AAC(3)-II were the most common one (58\%) in E. coli [14]. Resistance to aminoglycosides in 16 ESBLproducing Enterobactericeae isolated in a Turkish hospital was explained by the presence of the $a a c(3)-I I$ and the $a a c\left(6^{\prime}\right)-I b-c r$ genes. Four of those isolates harbored an additional $\operatorname{aph}\left(3^{\prime}\right)-I$ gene [15]. 
In this study, the second most common AME gene was aac(3)-IIa, which causes resistance to gentamicin, netilmicin, and tobramycin [4]. In the isolates containing this gene, resistance rates to gentamicin (95.4\% with $\mathrm{MICs} \geq 16 \mathrm{mg} / \mathrm{L})$ and tobramycin $(96.9 \%)$ are in agreement with the expected phenotype. In addition, eight isolates (9\%) harboring aph $\left(3^{\prime}\right)$-Ia co-harbored the aac (3')-IIa gene, and were resistant to gentamicin. The APH $\left(3^{\prime}\right)-\mathrm{I}$ subclass shows a resistance profile including kanamycin and neomycin and is widely distributed among Gram-negative bacteria containing wide host range plasmids and transposons [4].

ANT( $\left.2^{\prime \prime}\right)$-Ia is also commonly encoded by plasmids and transposons and mediates resistance to gentamicin, tobramycin, and kanamycin [4]. We found the ant (2")-Ia gene in only two E. coli isolates, which were resistant to both gentamicin and tobramycin.

Among the Syrian patients $(n=17)$, the most prevalent gene was aac(3)-IIa $(82.3 \%)$, followed by $a a c\left(6^{\prime}\right)-I b(64.7 \%)$ and $a p h\left(3^{\prime}\right)-I a(5.8 \%)$. The most frequent association was $a a c(3)-I I a$ and $a a c\left(6^{\prime}\right)-I b$ (52.9\%). To the best of our knowledge, this is the first report of AMEs resistance from Syrian patients in Turkey.

$K$. pneumoniae and $P$. aeruginosa showing high-level resistance to clinically useful aminoglycosides through the production of acquired methyltransferases were identified in France and Japan, respectively, in 2003 [9, 16]. These enzymes are mostly located on transferable plasmids, and could be easily transferred to other bacterial species [5]. In this study, the $r m t C$ gene was identified in a single K. pneumoniae isolated from a blood culture, which does not harbor any of the studied AME genes, produce an ESBL, and was also carbapenem-resistant. MICs of amikacin and gentamicin for this organism are $>64$ and $>16 \mathrm{mg} / \mathrm{L}$, respectively. In Turkey, the $r m t C$ gene has been previously detected in four $K$. pneumoniae isolates resistant to both amikacin (MIC $>512 \mathrm{mg} / \mathrm{L}$ ) and gentamicin $(\mathrm{MIC}>128 \mathrm{mg} / \mathrm{L})$ and producing the NDM-1 carbapenemase [17]. The $\mathrm{rmt} B$ gene has also been identified in an aminoglycoside-resistant $K$. pneumoniae isolate in Turkey. This represented the first report in Turkey of a clinical isolated with a single plasmid containing the genes $r m t B$, qep $A$, and $b_{\mathrm{CTX}-\mathrm{M}-15}$ [10]. On the other hand, resistance due to $16 \mathrm{~S}$ rRNA methyltransferases was not found in any of 37 aminoglycoside-resistant Turkish clinical isolates with an amikacin $\mathrm{MIC} \geq 128$ [18].

In conclusion, resistance to aminoglycosides in clinical isolates of $E$. coli and $K$. pneumoniae isolated in Gaziantep is predominantly caused by the $\mathrm{AAC}\left(6^{\prime}\right)-\mathrm{Ib}$ and the AAC(3)-II enzymes, while the occurrence of $16 \mathrm{~S}$ rRNA methylases is so far limited. Further studies are needed to determine the importance of AMEs and 16S rRNA methyltransferase as causes of aminoglycoside resistance in Turkey. 


\section{Conflict of Interest}

The authors declare no conflict of interest.

\section{References}

1. Miró, E., Grünbaum, F., Gómez, L., Rivera, A., Mirelis, B., Coll, P., Navarro, F.: Characterization of aminoglycoside-modifying enzymes in Enterobacteriaceae clinical strains and characterization of the plasmids implicated in their diffusion. Microb Drug Resist 19, 94-99 (2013).

2. Fernandez-Martınez, M., Miro, E., Ortega, A., Bou, G., Gonzalez-Lopez, J. J., Oliver, A., Pascual, A., Cercenado, E., Oteo, J., Martınez-Martınez, L., Navarro, F.: Spanish network for the research in infectious diseases (REIPI): Molecular identification of aminoglycoside modifying enzymes in clinical isolates of Escherichia coli resistant to amoxicillin/ clavulanic acid isolated in Spain. Int J Antimicrob Agents 46, 157-163 (2015).

3. http:/www.euro.who.int/en/health-topics/disease-prevention/antimicrobial-resistance/ publications/2016/central-asian-and-eastern-european-surveillance-of-antimicrobial-resistance. annual-report-2016.

4. Ramirez, M. S., Tolmasky, M. E.: Aminoglycoside modifying enzymes. Drug Resist Update 13, 151-171 (2010).

5. Wachino, J., Arakawa, Y.: Exogenously acquired 16S rRNA methyltransferases found in aminoglycoside-resistant pathogenic Gram-negative bacteria: An update. Drug Resist Updat 15, 133-148 (2012).

6. Haldorsen, B. C., Simonsen, G. S., Sundsfjord, A., Samuelsen, O., Norwegian Study Group on Aminoglycoside Resistance: Increased prevalence of aminoglycoside resistance in clinical isolates of Escherichia coli and Klebsiella spp. in Norway is associated with the acquisition of AAC(3)-II and AAC(6£)-Ib. Diagn Microbiol Infect Dis 78, 66-69 (2014).

7. Clinical and Laboratory Standards Institute: Methods for Dilution Antimicrobial Susceptibility Tests for Bacteria that Grow Aerobically; Approved Standard, $9^{\text {th }}$ Edition. Document M07-A9. CLSI, Wayne, PA, 2012.

8. Park, C. H., Robicsek, A., Jacoby, G. A., Sahm, D., Hooper, D. C.: Prevalence in the United States of $a a c\left(6^{\prime}\right)-I b-c r$ encoding a ciprofloxacin-modifying enzyme. Antimicrob Agents Chemother 50, 3953-3955 (2006).

9. Galimand, M., Courvalin, P., Lambert, T.: Plasmid-mediated high-level resistance to aminoglycosides in Enterobacteriaceae due to $16 \mathrm{~S}$ rRNA methylation. Antimicrob Agents Chemother 47, 2565-2571 (2003).

10. Fritsche, T. R., Castanheira, M., Miller, G. H., Jones, R. N., Armstrong, E. S.: Detection of methyltransferases conferring high-level resistance to aminoglycosides in Enterobacteriaceae from Europe, North America, and Latin America. Antimicrob Agents Chemother 52, 1843-1845 (2008).

11. Doi, Y., Arakawa, Y.: 16S ribosomal RNA methylation: Emerging resistance mechanism against aminoglycosides. Clin Infect Dis 45, 88-94 (2007). 
12. Castanheira, M., Fritsche, T. R., Sader, H. S., Jones, R. N.: RmtD 16S RNA methylase in epidemiologically unrelated SPM-1-producing Pseudomonas aeruginosa isolates from Brazil. Antimicrob Agents Chemother 52, 1587-1588 (2008).

13. Fernandez-Martinez, M., Ruiz del Castillo, B., Lecea-Cuello, M. J., Rodriguez-Bano, J., Pascual, A., Martinez-Martinez, L., Spanish Network for the Research in Infectious Diseases (REIPI), The Spanish Group for Nosocomial Infections (GEIH): Prevalence of aminoglycoside-modifying enzymes in Escherichia coli and Klebsiella pneumoniae producing extended spectrum $\beta$-lactamases collected in two multicenter studies in Spain. Microb Drug Resist 24, 367-376 (2018).

14. Over, U., Gür, D., Unal, S., Miller, G. H., Aminoglycoside Resistance Study Group: The changing nature of aminoglycoside resistance mechanisms and prevalence of newly recognized resistance mechanisms in Turkey. Clin Microbiol Infect 7, 470-478 (2001).

15. Bercot, B., Poirel, L., Ozdamar, M., Hakko, E., Turkoglu, S., Nordmann, P.: Low prevalence of $16 \mathrm{~S}$ methylases among extended-spectrum $\beta$-lactamase-producing Enterobacteriaceae from a Turkish hospital. J Antimicrob Chemother 65, 797-798 (2010).

16. Yokoyama, K., Doi, Y., Yamane, K., Kurokawa, H., Shibata, N., Shibayama, K., Yagi, T., Kato, H., Arakawa, Y.: Acquisition of 16S rRNA methylase gene in Pseudomonas aeruginosa. Lancet 362, 1888-1893 (2003).

17. Guven Gokmen, T., Nagiyev, T., Meral, M., Onlen, C., Heydari, F., Koksal, F.: NDM-1 and rmtC-producing Klebsiella pneumoniae isolates in Turkey. Jundishapur J Microbiol 9, e33990 (2016).

18. Ermertcan, S., Yilmaz, F. F., Tasli, H., Yurtman, A. N., Aydemir, S. S., Hosgor Limoncu, M.: Investigation of plasmid mediated methylase genes in aminoglycoside resistant Gram negative bacteria. Türk Mikrobiyol Cem Derg 43, 12-16 (2013). 